\title{
Effects of physical factors on the vertical distribution of larval walleye pollock Theragra chalcogramma under controlled laboratory conditions
}

\author{
Bori L. Olla, Michael W. Davis \\ Cooperative Institute for Marine Resource Studies, Northwest and Alaska Fisheries Center, National Marine Fisheries Service, \\ Hatrield Marine Science Center, Newport, Oregon 97365, USA
}

\begin{abstract}
Larval fish possess behavioral mechanisms which enable them to alter position in the water column to deal with vertical environmental gradients and select favorable conditions or avoid unfavorable ones. This study examined, under controlled laboratory conditions, behavioral responses of larval walleye pollock ( 4 to $8 \mathrm{~mm}$ ) to various physical factors that may potentially play a role in vertical movements and distribution. Diel periodicity in vertical distribution was evident and appeared to be under exogenous control. During the day, with light intensity at $70 \mu \mathrm{E} \mathrm{m}^{-2} \mathrm{~s}^{-1}$, larvae moved downward from the surface. As light intensity decreased during simulated evening twilight, larvae moved upward. At night, with no available light, larvae continued to swim upward, apparently the result of negative geotaxis. They remained near the surface until morning when they then began moving downward. Changes in vertical distribution occurred concomitantly with changes in activity, orientation and behavior. Formation of a vertical thermal gradient caused larvae to move upward and away from cold water. Turbulence at the surface, induced by an arrstream, elicited an avoidance response and resulted in larvae moving downward. Findings are compared with information from field studies and suggest how behavioral responses to a number of integrated factors can determine the vertical movement and distribution of larval walleye pollock.
\end{abstract}

\section{INTRODUCTION}

Zooplankton possess behavioral mechanisms which enable them to deal with vertical environmental gradients and alter position in the water column, selecting favorable conditions or avoiding unfavorable ones. For many species these types of movements are part of the daily cycle of activity with organisms migrating upward in one part of day or night and then reversing the process. Such movements are tied closely to the acquisition of food, avoidarce of predators and, since current may vary with depth, to horizontal dispersal. While vertical migration has been observed for all planktonic phyla (Longhurst 1976), much of what is understood about the mechanisms that control such movements comes from larval crustaceans (for review and discussion, see Sulkin 1984, Forward 1988). For fish larvae, most available information relating to the subject is on herring Clupea harengus (Woodhead \& Woodhead 1955, Blaxter 1973, Wales 1984, Batty 1987). The lack of such knowledge for larvae of other fish species makes it difficult to assign precise causes for their vertical distribution which may directly affect the efficacy of predictions of survival and recruitment success.

Walleye pollock Theragra chalcogramma Pallas is widely distributed in the North Pacific Ocean and Bering Sea and represents one of the largest fisheries in the world with more than 6 million mt being caught each year (FAO 1988). The larvae, which are limited in feeding by the lack of sufficient light (Paul 1983), reside primarily in the upper photic zone with the bulk of the distribution at depths less than $50 \mathrm{~m}$ (Kamba 1977. Cooney et al. 1978, Dagg et al. 1984, Kendall et al. 1987). Within this zone there is evidence for diel vertical movement with what appears to be a dominant crepuscular component (Kendall et al. 1987, Pritchett \& Haldorson 1988). Although these movements are generally correlated with light, no clear cause and effect relationships have been shown with this or any other factor. 
Our objectives in this study were to: (1) determine the age at which larvae were first capable of responding to light, (2) determine whether the pattern of diel vertical movement observed in field collections was present under controlled laboratory conditions, which would then make it possible to (3) examine the role that light, gravity and/or pressure, temperature and surface turbulence play in the vertical distribution of larvae, and (4) determine whether any degree of endogeny was involved in the diel pattern.

\section{MATERIALS AND METHODS}

Adult Theragra chalcogramma were collected by hook and line from Tacoma Narrows, Washington, USA $\left(47^{\circ} \mathrm{N}, 123^{\circ} \mathrm{W}\right)$ in February. Fish were transported to the laboratory and held in $1200 \mathrm{l}$ tanks in flowing, sandfiltered seawater $\left(10\right.$ to $12{ }^{\circ} \mathrm{C}, 30$ to $\left.32 \% \mathrm{~S}\right)$ and maintained on an artificial diet. Adults spawned naturally from March until the end of May and fertilized eggs were collected daily. Larvae (10 to $\left.25 \mathrm{l}^{-1}\right)$ were reared in $20 \mathrm{l}$ aquaria $(25 \times 50 \times 30 \mathrm{~cm})$ with opaque black sides and white bottoms, in a constant temperature room $\left(9^{\circ} \mathrm{C}\right)$ with a photoperiod of $12 \mathrm{~L}: 12 \mathrm{D}$. During the day, diffuse light was supplied from above by white fluorescent lamps (5000 K) giving $13.4 \mu \mathrm{E} \mathrm{m} \mathrm{m}^{-2} \mathrm{~s}^{-1}$ at the water surface. At night, light was supplied from a $25 \mathrm{~W}$ tungsten lamp $(3900 \mathrm{~K})$ giving $0.003 \mu \mathrm{E} \mathrm{m} \mathrm{m}^{-2} \mathrm{~s}^{-1}$ at the water surface. Light at higher light intensities 10.1 to 70 $\mu \mathrm{E} \mathrm{m}^{-2} \mathrm{~s}^{-1}$ ) was measured with a Licor $4 \pi$ sensor, while light at low light intensities $\left(<0.1 \mu \mathrm{E} \mathrm{m}^{-2} \mathrm{~s}^{-1}\right)$ was measured with an EG\&G model DR-1500 photometer and $2 \pi$ sensor. Readings with the photometer were taken in footcandles and converted to $\mu \mathrm{E} \mathrm{m}^{-2} \mathrm{~s}^{-1}$ assuming 1.0 footcandle $=0.13 \mu \mathrm{E} \mathrm{m}^{-2} \mathrm{~s}^{-1}$. Larvae were reared on rotifers Brachionus plicatilis which had been grown on the alga Isochrysis galbana (SERI strain ISOCH01). A third of the volume of each larval aquarium was siphoned out daily and rotifers (20 to $25 \mathrm{ml}^{-1}$ ) introduced over a period of $3 \mathrm{~h}$ in filtered $(0.2 \mu \mathrm{m})$ seawater replacing the water removed during siphoning. Larvae aged from 1 to $28 \mathrm{~d}$ post-hatch $(4$ to 8 mm length) were used in experiments.

Movement of pollock larvae (10 to $25 \mathrm{I}^{-1}$ ) in horizontal light gradients was measured to assess phototaxis in the absence of vertical light gradients and possible effects of larval age on movement. Larvae were counted in each half of a $20 \mathrm{l}$ aquarium described above. Then half of the aquarium was left uncovered (13.4 $\mu \mathrm{E} \mathrm{m}^{-2} \mathrm{~s}^{-1}$ ) while the other half was covered with layers of fiberglass screen which acted as neutral density filters to produce treatment light intensities of $1.9,3.9,5.4$ or $8.0 \mu \mathrm{E} \mathrm{m}^{-2} \mathrm{~s}^{-1}$. After $30 \mathrm{~min}$, larvae were counted in each half of the test aquarium and the numbers compared for statistical difference. Rotifers, measured by counting five $1 \mathrm{ml}$ samples, were present in the test aquaria with densities ( 20 to $25 \mathrm{ml}^{-1}$ ) remaining constant in both halves of the aquaria before and after trials (Sign test; $p>0.1$ ).

Responses of pollock larvae $(5.5$ to $7.5 \mathrm{~mm}$ length; 13 to $24 \mathrm{~d}$ post-hatch) to vertical gradients of light, gravity and/or pressure, turbulence and temperature were tested in 201 plexiglas cylinders $(15 \times 150 \mathrm{~cm})$, located in a constant-temperature, light-controlled room $\left(9^{\circ} \mathrm{C}\right)$. Stray light was kept at a minimum around the cylinders by a curtain of black polyethylene plastic sheeting. For each experimental treatment, 6 independent replicates were performed. Each replicate consisted of 50 to 70 larvae $\left(2.5\right.$ to $\left.3.5 \mathrm{1}^{-1}\right)$, aged from 10 to $12 \mathrm{~d}$ post-hatch, placed in a cylinder for up to $12 \mathrm{~d}$ with rotifers (20 to 30 $\mathrm{ml}^{-1}$ initially). Larvae were allowed to acclimate in the cylinders for $3 \mathrm{~d}$ before conducting an experiment and no water changes were made during the experiment. No significant abnormalities, mortality or change in growth of larvae were noted at the end of the treatments. Rotifer concentrations, measured by counting five $1 \mathrm{ml}$ samples per third of the cylinder, did not vary with depth during any treatment (Friedman test; $p>0.5)$.

A vertical light gradient was supplied from two $100 \mathrm{~W}$ tungsten lamps $(3900 \mathrm{~K})$ suspended above 2 cylinders. This configuration produced light which approximated normal angular light distribution essential for normal photic orientation (Forward 1988). Intensity $\left(\mu \mathrm{E} \mathrm{m} \mathrm{m}^{-2} \mathrm{~s}^{-1}\right)$ ranged from 70 at the water surface to 42 at $120 \mathrm{~cm}$ depth. Gradients of lower light intensities were produced by placing layers of neutral density fiberglass screening between the lights and the cylinders, creating intensities $\left(\mu \mathrm{E} \mathrm{m}^{-2} \mathrm{~s}^{-1}\right)$ ranging from 2.5 at the surface to 1.6 at $120 \mathrm{~cm}$ depth and 13.2 at the surface to 8.0 at $120 \mathrm{~cm}$ depth. Lower intensities were produced with a $25 \mathrm{~W}$ tungsten lamp (3900 K) yielding a surface intensity of $0.01 \mu \mathrm{E} \mathrm{m}^{-2} \mathrm{~s}^{-1}$

Surface turbulence, as a horizontal circular water motion, was produced by directing a compressed air stream ( 5 psi) from a $5 \mathrm{~mm}$ ID glass tube at the water surface in a cylinder Turbulence extended to $10 \mathrm{~cm}$ depth as determined by observed mixing of prey organisms

Thermoclines similar in temperature range, but vertically compressed, to those observed in the Gulf of Alaska (Kendall et al. 1987) were created by slowly introducing chilled seawater $\left(0^{\circ} \mathrm{C}\right)$ into the bottom of the cylinders until one third of the water had been replaced through overflow from the top of the cylinders. Temperature in the cylinders was measured $\left( \pm 0.5^{\circ} \mathrm{C}\right)$ with a mercury thermometer immersed to the depth of measurement. During thermocline conditions, temperature in the cylinders ranged from $9^{\circ} \mathrm{C}$ in 
the top half to $3{ }^{\circ} \mathrm{C}$ in the bottom third of the tube with this condition persisting for $2 \mathrm{~h}$ after cold water introduction. Temperature returned to pretest levels after $4 \mathrm{~h}$.

Distribution, orientation (angle of deviation from horizontal) and swimming patterns of larvae were measured in the cylinders by direct visual inspection and/or video recording during daylight conditions. During low light or night conditions the cylinders were illuminated from behind with $20 \mathrm{~W}$ infra-red lamps (Wratten 87 filter; $>780 \mathrm{~nm}$ ) and the larvae observed by infra-red sensitive video camera with the events recorded for subsequent analysis.

To measure vertical distribution, the number of larvae present in $20 \mathrm{~cm}$ sections of the cylinders were counted after a $30 \mathrm{~min}$ exposure to a particular treatment. The effect of light on larval distribution, orientation and swimming activity was determined by observing larvae under varying light intensities ranging from 0 to $70 \mu \mathrm{E} \mathrm{m} \mathrm{m}^{-2} \mathrm{~s}^{-1}$ over a simulated $24 \mathrm{~h}$ cycle. The presence of an endogenous rhythm in vertical migration was assessed by subjecting larvae to 36 h of continuous darkness and determining their distribution in the cylinders over time. To assess the relative roles that light and geotaxis and/or barotaxis played in vertical distribution, a light of low intensity $\left(4.1 \mu \mathrm{E} \mathrm{m}^{-2} \mathrm{~s}^{-1}\right)$ was placed beneath a cylinder and the resulting distribution of larvae noted. This distribution was compared with that resulting from illumination at the same intensity but from above.

The effect of turbulence on larvae was measured by comparing the distributions of the larvae in the top $10 \mathrm{~cm}$ of the cylinders before, during and after turbulence induction. The effect of thermoclines on larvae was measured by comparing the distributions before and during the presence of chilled seawater in the bottom third of the tube.

Each experimental treatment was replicated 6 times. The Friedman test and multiple comparisons, Sign test, U-test and Kruskall-Wallis test were used to compare treatment effects (Conover 1980). Statistical significance was considered at $p<0.05$ level. Median, first and third quartiles and ranges were calculated for groups of 6 replicates and used in figures.

\section{RESULTS}

Larval pollock (1 to 28 d post hatching) showed positive phototaxis in horizontal light gradients (Fig. 1; Friedman test, $\mathrm{p}<0.05$ ) with the magnitude of the response decreasing as differences in light intensity became less. Larvae were responsive soon after hatching, showing positive phototaxis $24 \mathrm{~h}$ after hatching with strength of the response fully developed after $4 \mathrm{~d}$

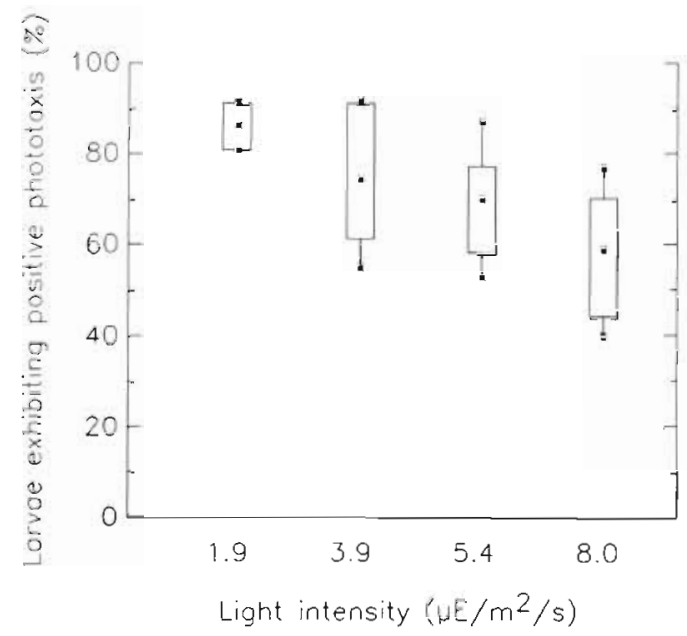

Fig. 1. Theragra chalcogramma. Walleye pollock larvae exhibiting positive phototaxis in a horizontal gradient. Choice was between ambient light intensity (13.4 $\left.\mu \mathrm{E} \mathrm{m}^{-2} \mathrm{~s}^{-1}\right)$ and lower intensities. Box plots show median, first and third quartiles and range of larval abundance $(\%)$ in ambient light for 6 replicate experiments. Larvae chose ambient light over all intensities tested $(1.9,3.9,5.4$ and 8.0$)$ at $p<0.05$ (Friedman test). distribution of larvae in ambient light was random (Sign test, $\mathrm{p}>0.10$ )

and continuing to $28 \mathrm{~d}$ (Fig. 2; Friedman test, $\mathrm{p}<0.05$ ). Larvae were unable to choose between 2 low intensities (Sign test, $\mathrm{p}>0.10$ ) approximating full moonlight $\left(0.003 \mu \mathrm{E} \mathrm{m} \mathrm{m}^{-2} \mathrm{~s}^{-1}\right)$ and less than quarter moonlight $\left(0.0003 \mu \mathrm{E} \mathrm{m} \mathrm{m}^{-2} \mathrm{~s}^{-1}\right)$.

A clear diel pattern of vertical movement was shown by the larvae (Fig. 3A). The largest percentage of larvae were closest to the surface $1 \mathrm{~h}$ before morning

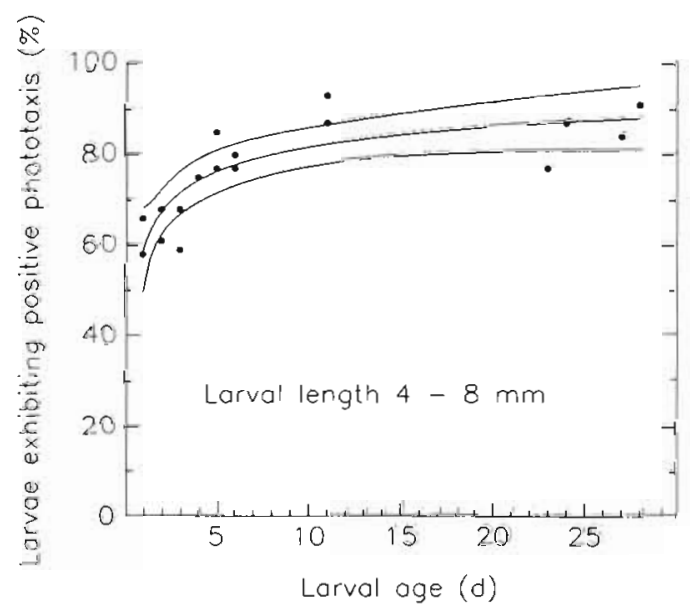

Fig. 2. Theragra chalcogramma. Effect of age of walleye pollock larvae exhibiting positive phototaxis in a horizontal gradient with choice between 13.4 and $1.9 \mu \mathrm{E} \mathrm{m}^{-2} \mathrm{~s}^{-1}$. Response was different from random distribution after $24 \mathrm{~h}$ and developed fully after $4 \mathrm{~d}(\mathrm{p}<0.05$, Friedman test). Fitted lines are mean and $95 \%$ confidence intervals for nonlinear regression 


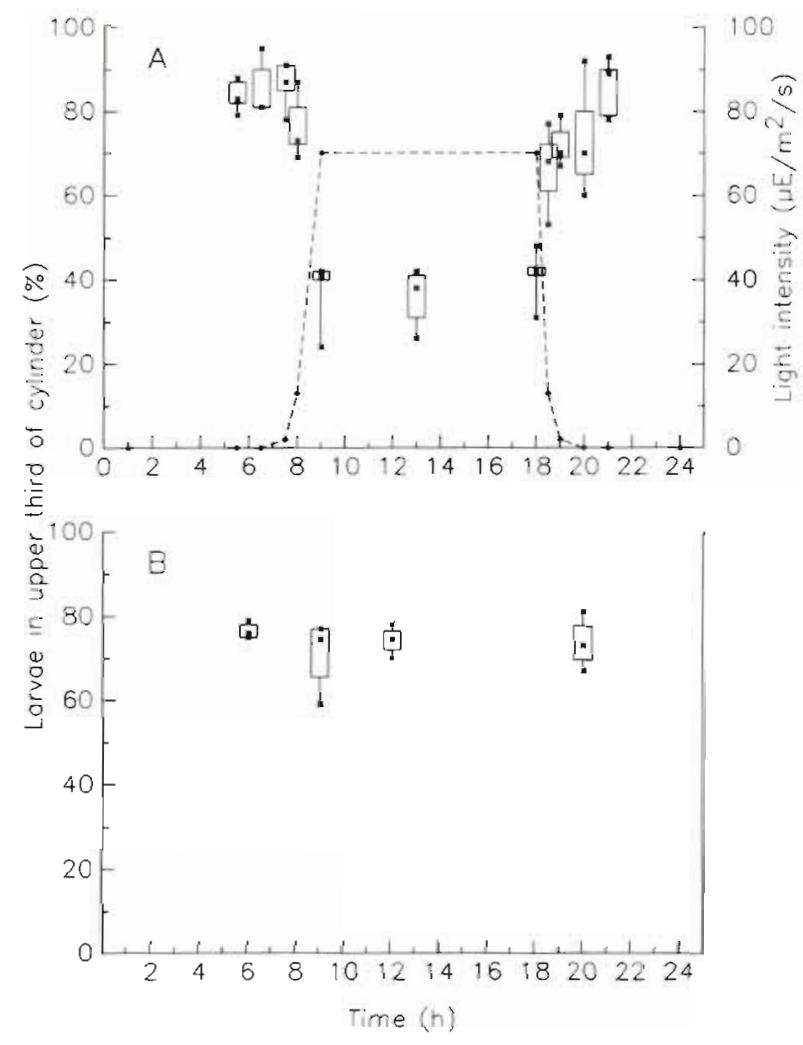

Fig. 3. Theragra chalcogramma. Vertical movement of walleye pollock larvae in a vertical cylinder during a $24 \mathrm{~h}$ cycle. Box plots show median, first and third quartiles and range of larval distribution $(\%)$ in upper third of 6 replicate cylinders. (A) Diel pattern of movement related to light intensity (dashed line) at surface of cylinder (B) Lack of vertical movement in constant darkness

light onset (Friedman test, $p<0.05$ ). During the gradual step-wise increase in light that simulated morning twilight, larvae remained in the upper layer until the light intensity reached $13 \mu \mathrm{E} \mathrm{m} \mathrm{m}^{-2} \mathrm{~s}^{-1}$ when they then showed a slight but significant shift downward (Friedman test, $\mathrm{p}<0.05$ ). During the day with light at the highest intensity $\left(70 \mu \mathrm{E} \mathrm{m} \mathrm{m}^{-2} \mathrm{~s}^{-1}\right)$, the largest percentage of larvae were distributed in the lower twothirds of the water column and remained there throughout this period (Fig. 3A; Friedman test, $p<0.05)$. Then as light intensity decreased in stepwise fashion during simulated evening twilight, they moved higher in the water columm. This trend continued as light intensity decreased further (Friedman test, $p<0.05$ ). Larvae swam into the upper layer of the water column in low light regardless of whether illumination was from the top or bottom of the experimental column (U-test, $\mathrm{p}=0.109$ ).

When larvae were held in constant darkness, they showed no change in vertical distribution, remaining in the upper layer of the column throughout the day and night (Fig. 3B; Friedman test, $\mathrm{p}=0.443$ ).
Changes in vertical distribution occurred concomitantly with changes in behavior. Individuals oriented primarily towards the horizontal during the day and primarily towards the vertical during the night (Fig. 4;

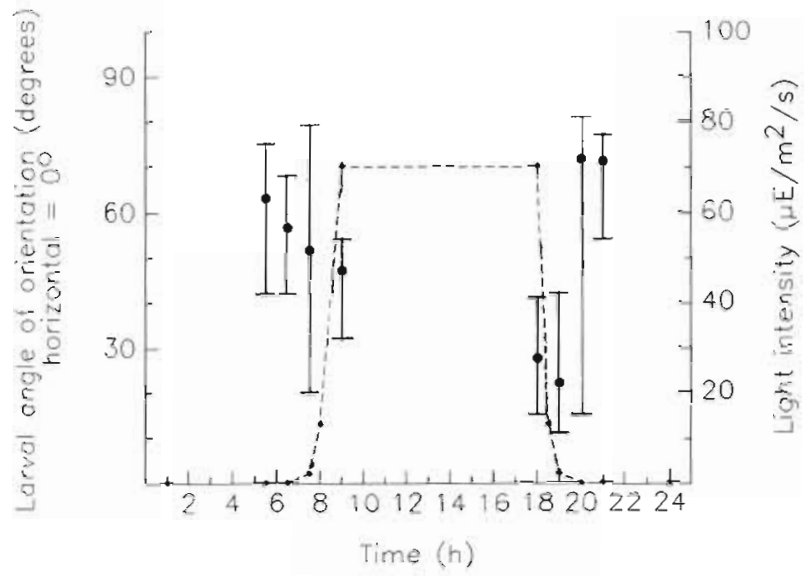

Fig. 4. Theragra chalcogramma. Larval angle of orientation as deviation from horizontal $\left(0^{\circ}\right)$ in a vertical cylinder during a 24 $h$ cycle. Values are median and first and third quartiles for 10 replicate larvae at each time sampled. Light intensity at surface of cylinder shown by dashed line

Kruskall-Wallis test, $\mathrm{p}<0.05)$. Swimming activity was greater by day than by night (Fig. 5A; Kruskall-Wallis test, $p<0.05$ ), while rest periods were shorter by day than by night (Fig. 5B; Kruskall-Wallis test, $\mathrm{p}<0.05$ ). Typically, swimming during daytime occurred in discrete, short bouts with a larva moving forward by executing a variable number of tail beats for a duration of $<1$ s with the distance covered ranging from less than $1 \mathrm{~cm}$ to $3 \mathrm{~cm}$. Equally common were multiples of up to 5 of these bouts strung together in succession with $<1$ s intervals between each bout. Each single or string of swimming bouts was followed by a rest phase with a larvae remaining stationary for 1 to $5 \mathrm{~s}$ (Fig. 5B). Forward swimming was associated with feeding as larvae sighted, approached, and ingested prey. Guts distended by food were readily discernible

With the onset of simulated evening twilight, as light intensity diminished in step-wise fashion, orientation of the larvae became highly variable (Fig. 4) and activity markedly decreased (Fig. 5A). Then in complete darkness, orientation of the larvae became significantly more vertical (Fig. 4; Kruskall-Wallis test, $\mathrm{p}<0.05$ ). Propulsion by tail beats was similar to that observed during the day but now was mainly in an upward direction (Fig. 4). Bouts of swimming that consisted typically of single discrete units were fewer in number than during the day (Fig. 5A; Kruskall-Wallis test, p < 0.05 ), but were longer in duration ( 1 to $3 \mathrm{~s}$ ). On occasion, up to 5 successive swimming bouts were strung 

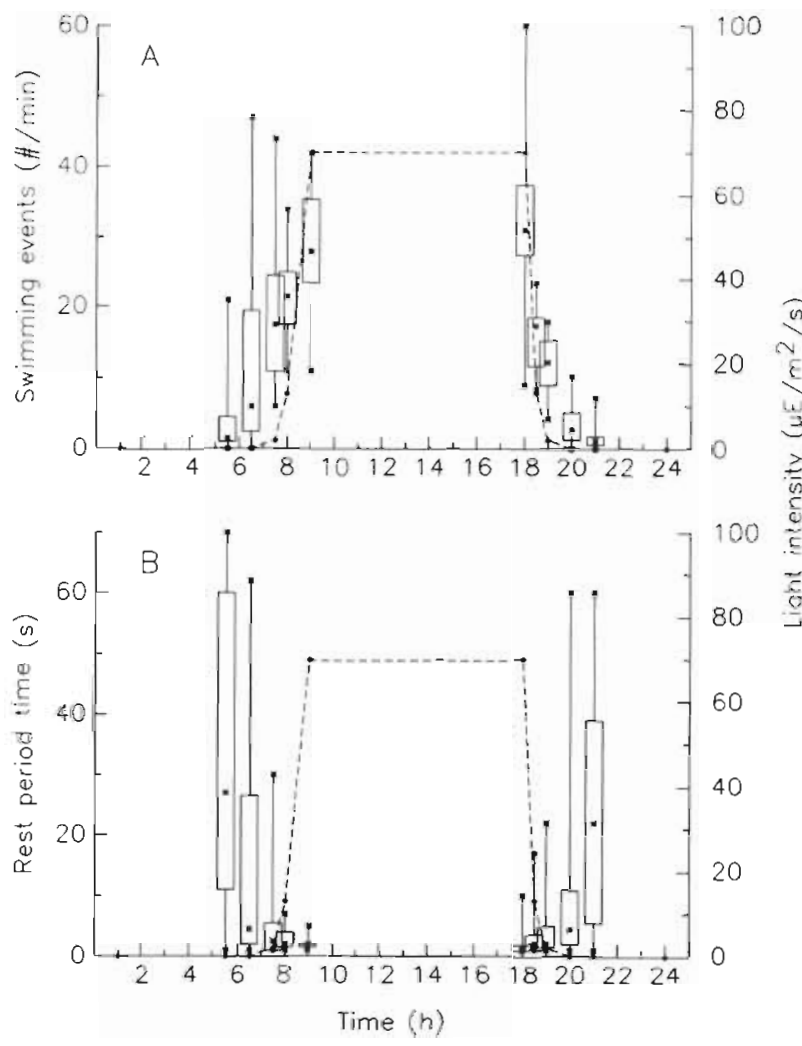

Fig. 5. Theragra chalcogramma. (A) Swimming events and (B) rest period times of walleye pollock in a vertical cylinder during a $24 \mathrm{~h}$ cycle. Box plots show median, first and third quartiles and range for 20 replicate larvae at each time sampled. Light intensity at surface of vertical cylinder shown by dashed line

together with momentary stops. The distance covered in each bout again was greater than during the day, ranging from 5 to $15 \mathrm{~cm}$. Swimming was followed by a rest phase that was significantly greater (Fig. 5B; Kruskall-Wallis test, $\mathrm{p}<0.05$ ) than those seen in the light. However, the rest phase in the dark was quite different from that in the light; when swimming stopped, a larva typically would turn from a head-up position to a headdown position and begin sinking. The duration of sinking ranged from 1 to $70 \mathrm{~s}$ and the distance traveled ranged from 0.25 to $15 \mathrm{~cm}$, with an average sinking speed of $0.20 \mathrm{~cm} \mathrm{~s}^{-1}$.

The introduction of cold water $\left(3^{\circ} \mathrm{C}\right)$ into the bottom third of an experimental cylinder elicited avoidance responses causing most of the larvae in that section of the cylinder $(65 \%)$ to move upward away from the thermocline, significantly altering their distribution (Fig. 6; Friedman test, p $<0.05$ ). The remaining $35 \%$ of the larvae in the lower third of the cylinder did not show avoidance and became entrained in the cold water beneath the thermocline. Entering cold water caused immediate torpor and the larvae slowly sank to

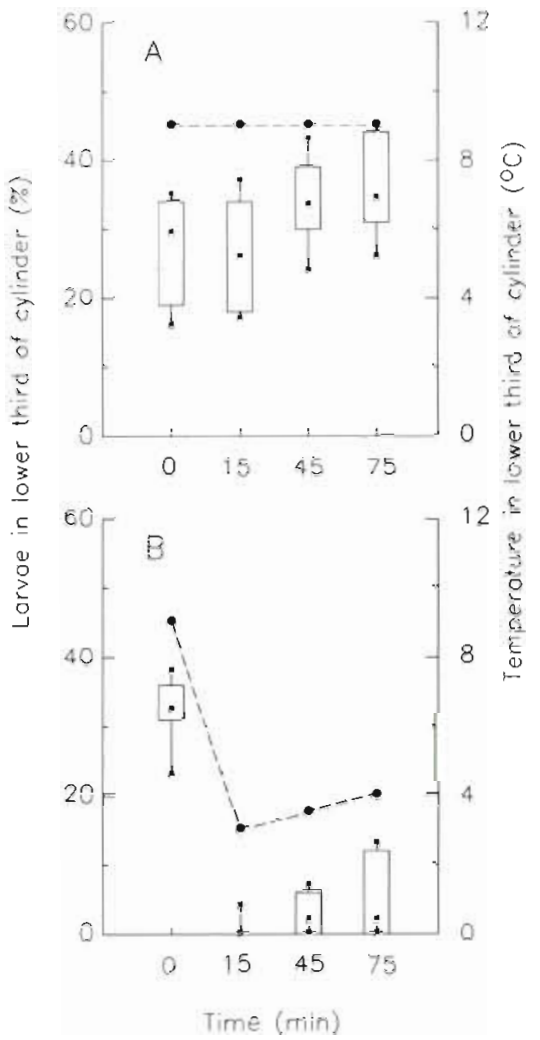

Fig. 6. Theragra chalcogramma. Effect of thermocline on vertical movement of walleye pollock larvae in a vertical cylinder. Box plots show median, first and third quartiles and range of larval abundance (\%) in lower third of 6 replicate cylinders. Time is min after stability was achieved for homothermal seawater $\left(A ; 9^{\circ} \mathrm{C}\right)$ or chilled seawater $\left(B ; 3{ }^{\circ} \mathrm{C}\right)$. Temperature in lower third of cylinder is shown by dashed lines. Light intensity at surface of the cylinder was $70 \mu \mathrm{E} \mathrm{m}^{-2} \mathrm{~s}^{-1}$

the bottom of the experimental cylinder where they remained totally quiescent. When temperature returned to pretest levels $4 \mathrm{~h}$ later, the larvae on the bottom resumed normal activity.

Larvae apparently could detect and respond to turbulence (Fig. 7). Avoidance of surface turbulence altered their distribution downward (Friedman test, $p<0.05$ ).

\section{DISCUSSION}

Within $24 \mathrm{~h}$ after hatching, larval Theragra chalcogramma responded positively to light. This observation is significant because it indicates that larvae which still possess a yolk sac, and are too underdeveloped to feed, have the capability to affect their distribution. Although our data are qualitative, they suggest that predictions of larval distribution based on water movements, even for larvae at this early age, should consider them to be more than passive particles. 


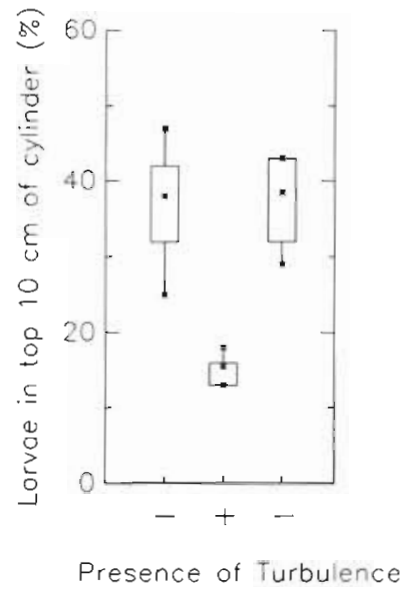

Fig. 7 Theragra chalcogramma. Effect of turbulence on vertical movement of walleye pollock in a vertical cylinder Box plots show median, first and third quartiles and range of larvae abundance $(\%)$ in top $10 \mathrm{~cm}$ of 6 replicate cylinders.

Light intensity at surface of cylinder was $13.2 \mu \mathrm{E} \mathrm{m}^{-2} \mathrm{~s}^{-1}$

The diel periodicity in vertical distribution apparently was under exogenous control with no endogenous component evident. Larvae held in the dark remained in the upper reaches of the experimental column and did not alter distribution vertically according to clock time. Exposing larvae to the dark at any time of the day caused them to swim upward and conversely to swim downward when light was raised to the highest intensity. In herring larvae Clupea harengus, Wales (1984) similarly found no indication of an endogenous rhythm of vertical migration either under constant darkness or light.

Positive phototaxis was apparent at low light intensities in horizontal light gradients. However, at higher light intensities in vertical cylinders, negative phototaxis would appear to be the most likely cause of larval Theragra chalcogramma moving downward during the day. The only other possible reason for descending would be if the prey (Brachionus plicatilis) in the column were negatively phototactic which in turn caused the larvae to follow in order to feed; this was not the case. Blaxter (1973) similarly found larval C. harengus moving downward from the surface under high light intensities. While a negative response to light caused larval $T$. chalcogramma to move downward, factor(s) other than light appeared to cause their movement upward in low light, i.e. twilight conditions. Larvae swam upward regardless of whether the experimental column was illuminated from the top or the bottom. In darkness, with no cues other than gravity or pressure present, movement was also upward. We conclude from these observations that negative geotaxis and/or barotaxis acting separately or in concert would be responsible for upward movement. Since in the present work pressure was not controlled for, it was not possible to discern whether larvae were responding to pressure or gravity. Woodhead \& Woodhead (1955) postulated a mechanism of negative geotaxis for larval $C$. harengus that, similar to larval $T$. chalcogramma, orient vertically and swim upward in darkness. Wales (1984) experimentally eliminated pressure confirming that the response, at least in $C$. harengus, is negative geotaxis. While it has not been clearly demonstrated that pressure mediates vertical migration in fish larvae, both pressure and gravity have been shown to play a role in this behavior in crustacean larvae with clear distinctions having been made between the two (see Sulkin 1984, Forward 1988 for review and discussion). Forward (1988), in reviewing the literature on vertical migration in crustacean larvae, concluded that negative geotaxis and barotaxis are mostly responsible for migration towards the surface with phototaxis appearing to play little or no role.

Since larval Theragra chalcogramma are lightlimited in feeding, upward movement beginning at evening twilight and continuing through the night would ensure that they are in the surface layers at the onset of morning twilight and could begin feeding as soon as light was sufficiently bright to permit it. Paul (1983) found that the threshold for feeding by $T$. chalcogramma was $0.006 \mu E \mathrm{~m}^{-2} \mathrm{~s}^{-1}$ which, when extrapolated to the field, would mean that light sufficient for feeding would be available for 12 to $14 \mathrm{~h}$ per day at 10 to $30 \mathrm{~m}$ depth in the southeastern Bering Sea during the larval season. In the experimental column, when light reached the maximum intensity $\left(70 \mu \mathrm{E} \mathrm{m}^{-2} \mathrm{~s}^{-1}\right)$, the larvae moved downward and remained there throughout the day, moving upward again when light decreased. Light at this maximum intensity would be available at approximately $20 \mathrm{~m}$ at midday in the Gulf of Alaska, assuming Type III water characteristics as defined by Jerlov (1976). Kendall et al. (1987) found that the bulk of larval $T$. chalcogramma (10 to $12 \mathrm{~mm}$ ) in the Gulf of Alaska were below 20 m during midday.

Larval Theragra chalcogramma were more active by day than by night; similar to observations on Clupea harengus (Woodhead \& Woodhead 1955, Blaxter 1973, Batty 1987). Decreased activity at night might serve several possible functions. Since larvae are lightljmited in feeding, it would be advantageous from an energetic point of view to be less active and conserve energy at a time when feeding and energy input is absent. Even when active, the principal activity was intermittent vertical swimming which may be more efficient and energy-saving than continuous vertical swimming (Haury \& Weihs 1976, Webb \& Weihs 1986). Some larval clupeoids have taken energy savings at night a step further by filling their gas bladders with air each night and thereby reducing the amount of swim- 
ming necessary to maintain position in the water column (Uotani 1973, Hunter \& Sanchez 1976, Hoss \& Phonlor 1984).

It is likely that rods in the retinae of walleye pollock larvae would be absent or less developed than cones, as in other larval fish (see Blaxter 1986 for review), which would make vision at night poor. Thus the ability to detect predators would be lessened with a dependence on other senses such as the inner ear, lateral line, or touch. Being less active would lower the potential encounter rate with predators and also conspicuousness to predators which would be advantageous at a time when responsiveness is lowest. Supporting this latter supposition is a study by Bailey \& Yen (1983) which showed that the susceptibility of Pacific hake Merluccius productus larvae to predation by the copepod Euchaeta elongata increased as larval activity increased.

While some field studies have shown no evidence for diel changes in vertical distribution in larval Theragra chalcogramma (e.g. Nishiyama et al. 1983, Clarke 1984, Dagg et al. 1984), others have observed such changes (Kamba 1977, Cooney et al. 1978, Haryu 1980, Kendall et al. 1987, Pritchett \& Haldorson 1988). Of these studies only the latter two provide sufficient data to detect more than gross day-night differences in vertical distribution. Sampling in the Gulf of Alaska, Kendall et al. (1987) found larvae (10 to $12 \mathrm{~mm}$ ) moved in to the upper water column during morning and evening twilight and then dispersed from the surface during the day and to a lesser extent at night. In Auke Bay, Alaska, Pritchett \& Haldorson (1988) showed larvae $>5.6 \mathrm{~mm}$ to disperse during midday and at night but to be near the surface during morning twilight, early morning and late afternoon. Except for the downward movement at night observed in both field studies, the results from the present study are consistent with results from these field studies.

Larval Theragra chalcogramma showed clear avoidance responses to both the presence of turbulence and a thermocline. Turbulence has been similarly shown to affect the vertical distribution of larval Clupea harengus under laboratory conditions (Batty 1987) and field conditions (Heath et al. 1988). It is unlikely that turbulence would act as an initiator of vertical migration but rather would alter distribution as a direct consequence of avoidance. We surmise the same would be true for thermoclines with the magnitude of avoidance response being dependent on the magnitude of the difference in temperature at the interface.

Larvae that became entrained in the cold water beneath the thermocline were not killed but rather became immediately torpid. All larvae, however, recovered and returned to normal activity when temperatures were raised to pretest levels. Thus this species, even at this early stage in its life history, possesses the physiological adaptation for the colder temperatures in which it will reside from late juveniles through adulthood. As juveniles, Theragra chalcogramma that remained beneath the thermocline for longer than several minutes, while not becoming torpid, did suffer some loss in orientation and decision making (Olla \& Davis 1990). After entrainment in cold water beneath a thermocline, prejuvenile red hake Urophysis chuss responded in much the same way as larval T. chalcogramma (Steiner \& Olla 1985).

In summary, behavioral responses to extrinsic factors such as gravity, light, thermal stratification, turbidity (as it would affect light penetration) and wind-driven surface turbulence play a role in determining the vertical movements and distribution of Theragra chalcogramma larvae. Intrinsic factors not considered in the present work such as feeding motivation (Olla \& Davis unpubl.) and extrinsic factors such as prey distribution (Munk et al. 1989) we assume would also play a significant role in vertical movements and distribution. A clearer understanding of how all of these and other factors are integrated will contribute to more realistic predictions of larval distribution, recruitment and survival.

\section{LITERATURE CITED}

Bailey, K. M., Yen, J. (1983). Predation by a carnivorous marine copepod, Euchaeta elongata Esterly, on eggs and larvae of the Pacific hake, Merluccius productus. J. Plankton Res. 5: 71-82

Batty, R. S. (1987). Effect of light intensity on activity and foodsearching of larval herring, Clupea harengus: a laboratory study. Mar. Biol. 94: 323-327

Blaxter, J. H. S. (1973). Monitoring the vertical movements and light responses of herring and plaice larvae. J. mar biol. Ass. U. K. 53: 635-647

Blaxter, J. H. S. (1986). Development of sense organs and behaviour of teleost larvae with special reference to feeding and predator avoidance. Trans. Am. Fish. Soc. 115: 98-114

Clarke, M. E. (1984). Feeding behavior of larval walleye pollock, Theragra chalcogramma (Pallas) and food availability to larval pollock in the Southeastern Bering Sea. Ph. D. thesis, Univ. of California, San Diego

Conover, W. J. (1980). Practical nonparametric statistics. J. Wiley \& Sons, New York

Cooney, R. T., English, T. S., Nishiyama, T (1978). Upper trophic level ecology with emphasis on juvenile pollock in the Southeast Bering Sea. In: PROBES: Processes and resources of the Bering Sea shelf. Prog. Rep. Inst. Mar. Sci, Univ. Alaska, Fairbanks, p. 241-385

Dagg, M. J., Clarke, M. E., Nishiyama, T., Smith, S. L. (1984) Production and standing stock of copepod nauplii, food items for larvae of the walleye pollock Theragra chalcogramma in the southeastern Bering Sea. Mar Ecol. Prog. Ser. 19: 7-16

Food and Agriculture Organization (1988). Yearbook of fishery statistics, Vol. 62. FAO, Rome 
Forward, R. B., Jr (1988). Diel vertical migration: zooplankton photobiology and behaviour Oceanogr. mar Biol. A. Rev. 26: 361-393

Haryu, T. (1980). Larval distribution of walleye pollock. Theragra chalcogramma (Pallas), in the Bering Sea with special reference to morphological changes. Bull. Fac. Fish. Hokkaido Univ. 31: 121-136

Haury, L., Weihs, D. (1976). Energetically efficient swimming behavior of negatively buoyant zooplankton. Limnol. Oceanogr. 21 797-803

Heath, M. R., Henderson, E. W., Baird, D. L. (1988). Vertical distribution of herring larvae in relation to physical mixing and illumination. Mar. Ecol. Prog. Ser. 47: 211-228

Hoss, D. E., Phonlor, G. (1984). Field and laboratory observations on diurnal swim bladder inflation-deflation in larvae of gulf menhaden, Brevoortia patronus. Fish. Bull. U. S. 82: $513-517$

Hunter, J. R., Sanchez, C. (1976). Diel changes in swim bladder inflation of the larvae of the northern anchovy, Engraulis mordax. Fish. Bull. U. S. 74: 847-855

Jerlov, N. G. (1976). Marine optics. Elsevier Oceanography Series 14. Elsevier Sci. Publ. Co, New York

Kamba, M. (1977). Feeding habits and vertical distribution of walleye pollock, Theragra chalcogramma (Pallas), in early life stage in Uchiura Bay, Hokkaido. Res. Inst. N. Pac. Fish., Hokkaido Univ. Spec. Vol. 175-197

Kendall, A. W., Jr, Clarke, M. E., Yoklavich, M. M., Boehlert, G. W. (1987). Distribution, feeding, and growth of larval walleye pollock, Theragra chalcogramma, from Shelikof Strait, Gulf of Alaska. Fish. Bull. U. S. 85: 499-521

Longhurst, A. R. (1976). Vertical migration. In: Cushing, A. R., Walsh, J. J. (eds.) The ecology of the seas. Blackwell Scientific Publications, Oxford, p. 116-446

Munk, P., Kiørboe, T., Christensen, V (1989). Vertical migrations of herring, Clupea harengus, larvae in relation to light and prey distribution. Environ. Biol. Fish. 26: 87-96

This article was presented by Dr R. S. Batty, Oban, United Kingdom
Nishiyama, T., Hirano, K., Haryu, T (1983). The early life history and feeding habits of larval walleye pollock Theragra chalcogramma (Pallas) in the Southeast Bering Sea. In: Symposium on Biology, Stock Assessment, and Management of Pollock, Pacific Cod, and Hake in the North Pacific Region. Int. North Pac. Fish. Comm., Vancouver, 1986. Bull INPFC 45, p. 177-227

Olla, B. L., Davis, M. W. (1990). Behavioral responses of juvenile walleye pollock Theragra chalcogramma Pallas to light, thermoclines and food: possible role in vertical distribution. J. exp. mar Biol. Ecol. 135: 59-68

Paul, A. J. (1983). Light, temperature, nauplii concentrations, and prey capture by first feeding pollock larvae Theragra chalcogramma. Mar. Ecol. Prog. Ser. 13: 175-179

Pritchett, M., Haldorson, L. (1988). Depth distribution and vertical migration of larval walleye pollock (Theragra chalcogramma). In: Proceedings of the International Symposium on the Biology and Management of Walleye Pollock. Lowell Wakefield Fish. Symp. Ser., 7th. Alaska Sea Grant Rep., no. 89-1, Univ. Alaska. Fairbanks, p. 173-183

Steiner, W. W. Olla, B. L. (1985). Behavioral responses of prejuvenile red hake, Urophycis chuss, to experimental thermoclines. Environ. Biol. Fish. 14: 167-173

Sulkin, S. D. (1984). Behavioral basis of depth regulation in the larvae of brachyuran crabs. Mar. Ecol. Prog. Ser. 15: 181-205

Uotani, I. (1973). Diurnal changes of gas bladder and behavior of postlarval anchovy and other related species. Bull. Jap. Soc. scient. Fish. 39: 867-876

Wales, W. (1984). Photic behaviour and vertical migration in herring larvae. Mar. Behav. Physiol. 11: 139-156

Webb, P. W., Weihs, D. (1986). Functional locomotor morphology of early life history stages of fishes. Trans. Am. Fish. Soc. 115: $115-127$

Woodhead, P. M. J., Woodhead, A. D. (1955). Reactions of herring larvae to light: a mechanism of vertical migration. Nature, Lond. 176: 349-350

Manuscript first received: December 21, 1989

Revised version accepted: March 22, 1990 